\title{
HABITAT UTILISATION PATTERN OF Lantana camara IN UDAWALAWE NATIONAL PARK IN SRI LANKA
}

\author{
W.N.N.U. Gunatilleke' \& D.M.S.H.K. Ranasinghe ${ }^{2}$ \\ 1 Department of Wild life Conservation \\ 2 Department of Foresty \& Environmental Science, \\ University of Sii Jayewardenepura
}

Lantana camara, of the family Verbenaceae is native to the tropical and sub tropical regions of Central and South America. It grows in a wide range of habitats, from exposed dry hillsides to wet heavily shaded gullies. It was introduced to Sri Lanka in 1926 through the Royal Botanic Gardens and currently it has spread across the island significantly and has become an invasive species in most of the habitats including the Udawalawe National Park. Through its invasive nature it has become a threat to fauna and flora of the Park due to habitat invasion and loss. Therefore, the main objective of this study is to assess the habitat utilization pattern of $L$. camara in the Park.

For this, the extent of the species in the 3 selected habitats of the Park ic. Scrub grassland, Medium height scrub and Scrub forest transitions was studied using field survey using GPS instruments. This data was mapped subsequently in order to get an overall idea of the habitat utilization of the species in the Park. Further, the relative abundance of this species in each of the 3 habitats selected was studied using $10 \times 10 \mathrm{~m}$ quadrates replicated 3 times for better accuracy. Field observations were carried out in L. camara trees on the following parameters, presence of flowers and seeds on the tree, time taken to start flowering, seed dispersal mechanism, seed germination an 1 spreading ability. Seeds were also germinated in the green house of the University of Sri Jayewardenepura to assess the germination period and germination energy.

The results showed significant variation was observed between the habitat types sampled in the extent of L. camara; the figures being $75 \%$ in the Scrub grassland, $65 \%$ in Medium height scrub and $45 \%$ being in the Scrib forest transitions. When these results werc mapped, it showed $20 \%$ invasion of L. camara in the Park especially into the vegetation types sampled in the study. When taken as an overview, the main road and Veheragolla, Seenuggala, Mau ara, Thimbiriyamankad $t$ and $5^{\text {th }}$ mile post are the most densely and continuously distributed areas.

The relative abundance and height of $L$. camara was highest in the Medium height scrub grassland $(92 \%)$ while the lowest was observed in the Scrub forest transitional area (87\%). The species produced large number of flowers and seeds ( $20-30 /$ cluster). The germination ability of the plant was very high $(85 \%$. Therefore, the present study highlights the invasive nature of the plant especially in open scrub areas and the need to effectivcly mange the same to secure the biodiversity of the Park.

Proceedings of the Eighth Anmual Forestry and Environment Symposium 2002 of the Department of Forestry and Environmental Science, Cniversity of Sri Jayewardenepura, Sri Lanka 